See Article page XXX.

\section{Commentary: More ado about nothing: Resect "versus" respect and left ventricular function after repair}

\author{
Patrick M. McCarthy, MD
}

Recently data were published showing the equivalence of resect and respect techniques on left ventricular (LV) function in patients with degenerative mitral regurgitation. ${ }^{1}$ This excellent post-hoc analysis of a randomized study of 104 patients (the CAMRA Cardio-Link 2 study; Clinicaltrials. gov identifier NCT02552771) reports remarkably similar results. ${ }^{2}$ LV remodeling begins early after repair, as documented on predischarge echocardiogram. This is especially prominent with the reduction of LV end-diastolic volume and dimension index, and this improvement continued at 12-month follow-up. LV end-systolic volume and dimension index did not change predischarge, but both had reduced by the 12-month echocardiogram. Correspondingly, LV ejection fraction dropped about 10 points early $(61.1 \pm 5.4 \%$ preoperative vs $51.7 \pm 8.7 \%$ predischarge; $P<.0001)$. In addition, by 12 months and tracking the improvement in LV end-systolic volume index, the ejection fraction had improved $(56.4 \pm 5.1 \% ; P<.0001)$ but did not return to the preoperative level. This early reduction in LV ejection fraction, and only partial return to normal, has been reported before and likely reflects that we wait too long to operate on this group of patients. ${ }^{3-5}$ Asymptomatic, or

From the Division of Cardiac Surgery, Department of Surgery, Bluhm Cardiovascular Institute, Northwestern University Feinberg School of Medicine and Northwestern Medicine, Chicago, Ill.

Disclosures: Dr McCarthy reported Edwards Lifesciences: royalties and speaking fees; AtriCure and Medtronic: speaking fees; and Abbott REPAIR-MR Trial PI (unpaid).

The Journal policy requires editors and reviewers to disclose conflicts of interest and to decline handling or reviewing manuscripts for which they may have a conflict of interest. The editors and reviewers of this article have no conflicts of interest.

Received for publication Sept 20, 2021; revisions received Sept 20, 2021; accepted for publication Sept 22, 2021.

Address for reprints: Patrick M. McCarthy, MD, Division of Cardiac Surgery, Department of Surgery, Bluhm Cardiovascular Institute, Northwestern University Feinberg School of Medicine and Northwestern Medicine, 676 North Saint Clair St, Arkes Family Pavilion, Suite 730, Chicago, IL 60611 (E-mail: Patrick. McCarthy@nm.org).

J Thorac Cardiovasc Surg 2021; $\mathbf{\square}: 1-2$

$0022-5223 / \$ 36.00$

Copyright (c) 2021 by The American Association for Thoracic Surgery

https://doi.org/10.1016/j.jtcvs.2021.09.036

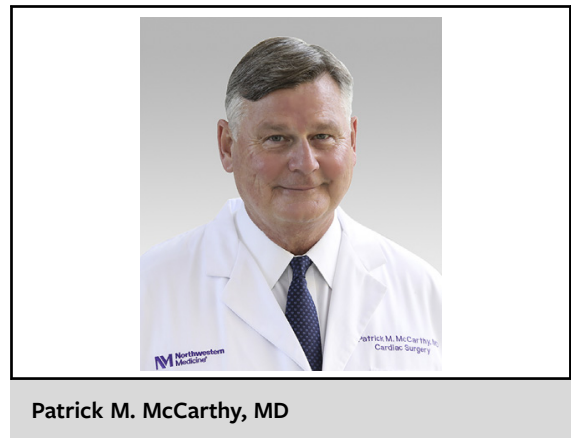

CENTRAL MESSAGE

The focus of mitral valve repair should be to leave no more than mild residual mitral regurgitation. Resect and respect are equally successful techniques.

mildly symptomatic patients, may be observed with "watchful waiting" until there are irreversible changes in LV function, which may reduce late survival. ${ }^{5}$ Other notable findings included an early and sustained reduction in pulmonary artery pressures and left atrial volume index. There was no change in tricuspid regurgitation over time (only 4 patients had tricuspid valve annuloplasty). As noted in the previous report, ${ }^{1,6}$ there was no appreciable physiologic difference in LV function between the leaflet resection and leaflet preservation (neochords) groups. Although both studies ${ }^{1,2}$ were small, the findings are quite similar in this respect, and the previous study ${ }^{1}$ also included global LV strain. The take-home point of repair with either strategy should be to leave no residual mitral regurgitation more than mild. Using a technique with which you are comfortable will provide the patient with durable freedom from recurrent mitral regurgitation. Both techniques work fine.

\section{References}

1. van Wijngaarden AL, Tomšič A, Mertens BJA, Fortuni F, Delgado V, Bax JJ, et al Mitral valve repair for isolated posterior mitral valve leaflet prolapse: the effect of respect and resect techniques on left ventricular function. J Thorac Cardiovasc Surg. February 22, 2021 [Epub ahead of print].

2. Hibino M, Dhingra NK, Verma S, Chan V, Quan A, Gregory AJ, et al. Mitral repair with leaflet preservation vs leaflet resection and ventricular reverse remodeling from a randomized trial. J Thorac Cardiovasc Surg. September 14, 2021 [Epub ahead of print].

3. Desai A, Thomas JD, Bonow RO, Kruse J, Andrei AC, Cox JL, et al. Asymptomatic degenerative mitral regurgitation repair: validating guidelines for early intervention. J Thorac Cardiovasc Surg. 2021;161:981-94.e5. 
4. Suri RM, Schaff HV, Dearani JA, Sundt TM, Daly RC, Mullany CJ, et al. Recovery of left ventricular function after surgical correction of mitral regurgitation caused by leaflet prolapse. J Thorac Cardiovasc Surg. 2009;137:1071-6.

5. Enriquez-Sarano M, Suri RM, Clavel MA, Mantovani F, Michelena HI, Pislaru S, et al. Is there an outcome penalty linked to guideline-based indications for valvular surgery? Early and long-term analysis of patients with organic mitral regurgitation. J Thorac Cardiovasc Surg. 2015;150: $50-8$.

6. McCarthy PM. Commentary: much ado about nothing: resect or respect? J Thorac Cardiovasc Surg. February 22, 2021 [Epub ahead of print]. 